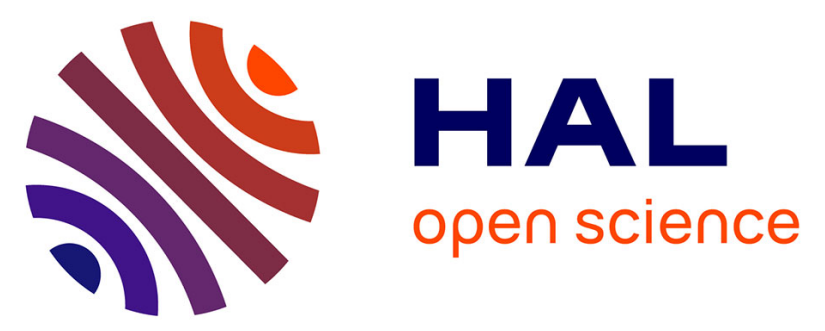

\title{
Care About Your Customer: A Use and Gratification Study Regarding Co-creation and Customer Engagement on Facebook
}

Patrick Cornelissen, Robin Effing, Ton Spil

\section{- To cite this version:}

Patrick Cornelissen, Robin Effing, Ton Spil. Care About Your Customer: A Use and Gratification Study Regarding Co-creation and Customer Engagement on Facebook. 18th Conference on e-Business, e-Services and e-Society (I3E), Sep 2019, Trondheim, Norway. pp.13-24, 10.1007/978-3-030-293741_2. hal-02510120

\author{
HAL Id: hal-02510120 \\ https://hal.inria.fr/hal-02510120
}

Submitted on 17 Mar 2020

HAL is a multi-disciplinary open access archive for the deposit and dissemination of scientific research documents, whether they are published or not. The documents may come from teaching and research institutions in France or abroad, or from public or private research centers.
L'archive ouverte pluridisciplinaire HAL, est destinée au dépôt et à la diffusion de documents scientifiques de niveau recherche, publiés ou non, émanant des établissements d'enseignement et de recherche français ou étrangers, des laboratoires publics ou privés.

\section{(c)(1)}

Distributed under a Creative Commons Attribution| 4.0 International License 


\title{
Care About Your Customer: A Use and Gratification Study Regarding Co-Creation and Customer Engagement on Facebook
}

\author{
Patrick Cornelissen ${ }^{[1]}$, Robin Effing ${ }^{[1,2]}$ and Ton A.M. Spil ${ }^{[1]}$ \\ ${ }^{1}$ University of Twente, P.O. Box 217, 7500 AE Enschede, The Netherlands \\ ${ }^{2}$ Saxion University of Applied Sciences, P.O. Box 70.000, \\ 7500 KB Enschede, The Netherlands \\ r.effing@utwente.nl
}

\begin{abstract}
Companies and their brands initiated various Co-creation practices on social media. Co-creation improves value for both companies and their customers. This study explored the customer perspective of interest for participating in such Co-creation opportunities on Facebook. Drawing upon the Use and Gratification Theory we investigated the intention of customers to take part in Co-creation on Facebook. We related people's Co-creation behaviour to the expectancy of satisfaction or reward for their actions. Customer Engagement is an additional concept that expresses the emotional attachment of customers to brands and companies. Underlying reasons were investigated why customers would consider taking part in Co-creation. The quantitative survey inquired customers about their expected Benefits, level of Customer Engagement and their intention for taking part in Co-creation with companies on Facebook. Our results showed that Customer Engagement can be considered as the most important predictor for the intention to Co-create instead of User Gratification. Hedonic Benefits are the most important drivers for User Gratification, playing a key role in the people's intention for taking part in Co-creation practices. Overall, people's intention for Cocreation on Facebook increases when they have a meaningful and pleasurable way of experiencing the companies' products that concern them.
\end{abstract}

Keywords: Social Media, Facebook, Social Network Sites, Customer Engagement, Consumer Engagement, Co-creation, Use and Gratification Theory.

\section{Introduction}

In 2019, Facebook exists 15 years and has more than 1.5 billion daily users. It was founded by Mark Zuckerberg from Harvard University for connecting with his fellow students in 2004 [1]. Facebook can be typified as a Social Networking Site. These sites give users the ability to make personal profiles and extend social life by befriending others [2]. Organizations can build a presence on Facebook since April 2006 and within two weeks over 4,000 organizations did so [3]. In Europe, over 307 million people are active on Facebook. More than 16 Million local business pages have been created since 
2013 and next to brand pages many social influencers now promote companies and brands.

The idea behind a social network site such as Facebook is to connect people and companies for bridging and bonding purposes such as Co-creation. Co-creation leads to a unique value for customers, resulting in a personal experience and therefore worthwhile for customers to take part in [4]. As a result from Co-creation practices, companies can ask premium prices for their products which contribute to higher profits $[4,5]$. Customers have various reasons to engage with companies and brands such as their desire or need for an emotional attachment with a company or Customer Engagement $[6,7]$. Overall, people expect some kind of benefit from engaging and co-creating on Facebook $[8,9]$. The Use and Gratification Theory can explain what benefits people expect and why they act [8-11]. However, this theory does not include a possible influence factor of Customer Engagement, emotional attachment or relationship. One previous study by Lee and Kim [8] did explore Co-creation on Social Media, but this study was limited to South-Korea and people that already took part in Co-creation. Furthermore, their study did not include Customer Engagement, which may be an important driver of Co-creation behaviour as well. Nambisan and Baron [9] did include Customer Engagement in their study but again among people that already Co-create.

Therefore, the main aim of this research is to understand why people want to start with Co-creation on Facebook. For this aim, we need to include Customer Engagement and emotional attachment regarding companies and brands. These may be important drivers of Co-creation next to the Perceived Benefits of receiving something in return. We want to refine a model of predictors and their effects on the intention to Co-create on Facebook. This paper explores people's willingness co-create with a company that is present on Facebook. Consequently, this study focuses on Perceived Benefits and Customer Engagement.

The remainder of this paper is structured as follows. First, this research shows a systematic literature review. In the next section, the research method is described including the data analysis approach. The results section is presenting the outcome of multi linear regression analysis. Finally, we present a discussion section including limitations and future research recommendations.

\section{Systematic Literature review}

This part of the paper examines existing literature on relevant subjects. The review starts with the Use and Gratification Theory with existing studies are outlined and reviewed in how they explain Co-creation. Thereafter, Customer Engagement is explored in depth and Facebook, Co-creation and Customer Engagement are outlined together. These factors may be important to explain human behavior in general and more specifically Co-creation here. Afterwards the conceptual model is drawn based on the Use and Gratification Theory and Customer Engagement. 


\subsection{The Use and Gratification Theory}

To understand why people would engage and/or Co-create on Facebook with a company, the Use and Gratification Theory is useful. Basically, people seek some sort of gratification for their actions [8-12]. Although this theory is not always explicitly used, the idea of fulfilling goals and needs in regard to using Social Media, engaging and Cocreation is mentioned more often [13-15]. Nambisan and Baron [9] explain why people engage and Co-create from a motivational perspective expecting a kind of gratification from Co-creation on virtual customer environments. There are four motivations as a base for people's action that lead to perceived benefits for the people involved.

First, Cognitive or learning benefits in order to improve usage of products and technologies. Second, Social Integrative benefits which creates a sense of community and one's own social identity. Third, Personal Integrative benefits which gives a sense of accomplishment. Fourth and last, Hedonic benefits which is about pleasure and intellectual stimulants from participating in discussions and such. These motivations of people improve engagement and Co-creation efforts. However, these authors looked into what people that already Co-create on a virtual customer site expect from their actions.

Fig. 1. Research model of Lee and Kim in [8]

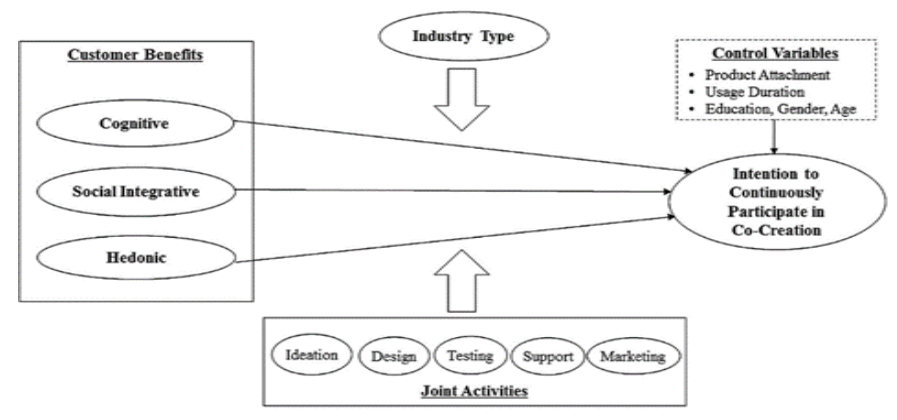

Lee and Kim [8] explored why people intend to Continuously Co-create on corporate controlled Social Networking Sites such as Facebook and Twitter through a survey. They asked participants about their most important Co-creation activity, on the longterm and what they expected from their Co-creation. Lee and Kim use the Expectancyvalue theory and additionally what value people derive from different Co-creation activities. These benefits are similar to the benefits in the Use and Gratification theory. (Figure 1) Lee and Kim's [8] study did include Facebook as place for Corporate Social Networking Sites, their study was not specific to Facebook itself or Social Media outside a corporate managed domain. Additionally, it is restricted to South Korea as Lee and Kim note [8] as a limitation. Furthermore, they looked into long-term duration, instead of why people start to engage and Co-create. 


\section{Customer Engagement and Conceptual Model}

Customer Engagement is an emotional attachment, a bond or a psychological state of mind towards a firm $[5,6,14,16]$. Other views look at Customer Engagement as a behavioural manifestation and something that is relational in nature [7, 15, 17-19]. However, Customer Engagement is always a long term and interactive phenomenon between company and customer. People engage because they want to experience more value-in-use $[6,14,15,19,20]$ or be entertained $[6,18]$. But relevant here is the emotional or relationship value people expect from engaging with companies $[6,15,21]$. People may start to advocate or advertise on behalf of the company when they are engaged [22]. Engagement ranges from interaction, then participation and towards Cocreation itself as highest level [7] and people even start to help in production [17].

\subsection{Underlying dimensions of Customer Engagement}

Customer Engagement is a very broad term in itself and often not well defined. However, this part explains the dimensions used in the survey more in depth. Importance is connected to one's own identity and goals [15], while in [9] importance is mentioned to perceived importance and product involvement. Lee and Kim [8] use importance in connection to the use of a product or service. Relevance is connected to possible benefits [9], but does not give a definition of relevance in itself. Likewise, Lee and Kim [8] do not define relevance of a product, but seem to connect this with the regular use or daily need of a product or service. Meaning, Nambisan and Baron [9] point out that meaning comes from long-term interactions with other community members. Sashi [22] too points at long term interactions, but this is focused on the company itself. However, Brodie et al. [7] mention that meaning comes from a connection to work or daily life in the broadest sense. Concern, again Lee and Kim [8] use this in relation to the use of products and services, but offer no definition or explanation on how a product may concern someone. Nambisan and Baron [9] mention concern in relation to product attachment, indicating an emotional reason. Overall, it is unclear where these underlying dimensions really differ from one and other. Importance and Relevancy appear more connected to the use of a product or service itself. While Meaning is related to longterm relationships and Concern seems to be affectional.

\subsection{Facebook, Customer Engagement and Co-creation}

These parts show where the subjects of Facebook, Customer Engagement and Co-creation overlap and relate to each other. People look for relationships with others and communities on Facebook [23], being able to receive information about friends and interests posted on profiles [11]. However, people can connect and relate to a shared object such as a company too [23]. Facebook gives companies and customers the ability to reach out and connect to each other [24]. People have various reasons to engage with companies, Muntinga et al. in [10] mention that people seek a kind of gratification. Similarly, Phua et al. [11] mention the need for gratification on Facebook such as socializing and entertainment. The interactive nature of Facebook strengthens the 
relationship value and community [25], which stimulates relationships to become longterm and emotional [26].

As a result, Facebook is an effective place to engage with customers. As people engage on Facebook with companies, they start to share content, comment on content and create their own content $[24,27,28]$. People are actually providing marketing work for the company such as word-of-mouth [24, 29]. Furthermore, people can provide support to others, test products or even help create them [8]. Customer Engagement and Cocreation are related to each other. While Co-creation may always be present, the active participation of Customer Engagement is not always there [13, 14]. People start to actively Co-create when they become engaged to the company [14, 15, 24, 30, 31]. Facebook allows people to interact through personalized profiles and possibly interact with a company of their choosing. The value of a product or a service also depends on the customer [32]. Co-creation can provide benefits for people and companies and people may intent to Co-create when they expect something in return.

\subsection{Conceptual Model}

From the Use and Gratification theory, the following conceptual model (Figure 2) is drawn. People may be willing to Co-create when they expect benefits from that action. These benefits come from Cognitive, Social, Personal or Hedonic causes. Lee and Kim in [8] found that the control variables Usage duration, Education, Gender and Age were not significant and therefore left out in the survey of this study. They found that the control variable Product attachment is important, however, attachment is larger than a single product and can extend to a brand or a whole company. Therefore, Customer Engagement may be a better control variable then Product attachment as Customer Engagement extents to a whole company.

Fig. 2. Conceptual Model

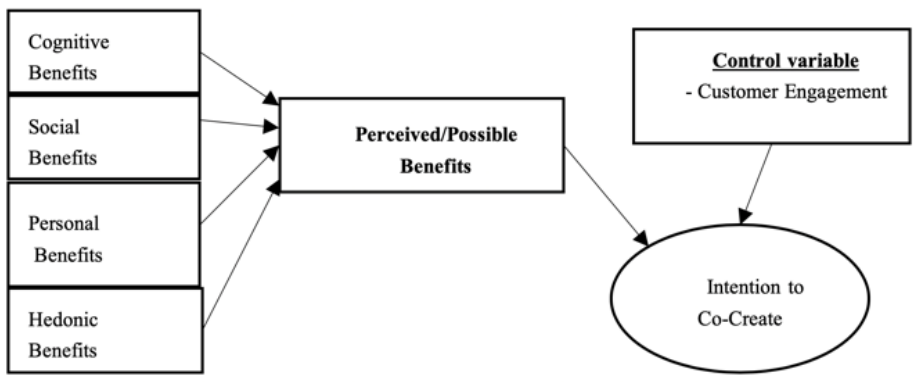

\section{$4 \quad$ Methodology and Hypotheses}

A structured literature review helped to find existing knowledge, theories and possible models $[33,34]$. Furthermore, it helped to investigate what is known, where opportunities for research exist and what possible relationships are between subjects [35]. In Table 1 we present our keyword phrases and terms. These terms were then filtered on 
the last decade for the most recent studies, filtered on Business as the context for this study and the filter Highly Cited was used to extract the most important articles from these. In order to collect data for this research, a survey with Likert questions that allow reliability, precision and the correct scope was used [36]. The questions were designed based on Lee and Kim [8] and Nambisan and Baron [9] in order to ask people about their dispositions on User Gratification and Customer Engagement. These measures are then analysed with Reliability measures, Validity measures and a Factor Analysis to review if they accurately represent their intended constructs. After this a multi linear regression was conducted to test the hypotheses mentioned below. Finally, the results of the regression are used to create the analysis model to show where and how the constructs relate to one and other.

Table 1. Search results from Keywords on Web of Science

\begin{tabular}{llll}
\hline Keywords & Total & Filtered & Included \\
\hline Customer Engagement & 18,966 & 16 & 8 \\
Co-Creation & 22,722 & 83 & 8 \\
Facebook & 13,410 & 17 & 9 \\
Facebook \& Customer Engagement & 328 & 8 & 6 \\
Facebook \& Co-creation & 66 & 30 & 6 \\
Co-Creation \& Customer Engagement & 448 & 20 & 8 \\
Facebook, Co-Creation \& Customer Engagement & 22 & 22 & 7 \\
\hline
\end{tabular}

Furthermore, to establish reliability and validity, Confirmatory Factor Analysis with an Oblique rotation is done to review the variables and their intended constructs as factors are expected to be correlated [37]. Additionally, Cronbach's Alpha, Composite Reliability, Convergent Validity and Divergent Validity are necessary statistics to establish reliability and validity of the measurements before modelling [37]. After this, single and multi linear regression are used to tests hypotheses and to build an appropriate model to reveal how constructs relate to each other. According to the Use and Gratification Theory, people expect certain benefits or values from their actions. Based on theory, as people expect higher Benefits from Co-creation on Facebook people will intend to co-create more on Facebook. Customer Engagement may be of influence on the benefits or a predictor for the intention to Co-create on Facebook in itself and therefore is expressed as a separate independent. From the use and Gratification Theory and Customer Engagement the following hypotheses are derived:

H1: Perceived Benefits increase the intention to Co-create.

- H1a: Perceived Cognitive Benefits increases the intention to Co-create.

- H1b: Perceived Social Benefits increases the intention to Co-create.

- H1c: Perceived Personal Benefits increases the intention to Co-create.

- H1d Perceived Hedonic Benefits increases the intention to Co-create.

H2: Customer Engagement mediates the relationship between Perceived Benefits and the intention to Co-create.

H3: Customer Engagement increases the intention to Co-create. 


\section{$5 \quad$ Data Collection and Results}

Data for this study has been collected through an online survey. The survey was spread through Facebook, LinkedIn and available student email lists of the university. The survey was sent on the $31^{\text {st }}$ of August 2018. Some reminders were sent during the time the survey was active and the survey closed on the morning of the $17^{\text {th }}$ of September 2018 with a total of $n=104$ replies and imported to SPSS.

Since this research has a theoretical model to test, a Confirmatory Factor analysis was conducted with an Oblique (direct Oblimin) rotation as factors are expected to be correlated (see Table 2). Factors with a loading of 0.55 or greater are to be included for a sample size of 104. There are no cross-loading variables showing that all Factors are unique (CB2; PB3, PB4; HB3; CE1, CE2 have been removed).

Table 2. Results Factor Analysis

\begin{tabular}{lcccccc}
\hline Factor & 1 & 2 & 3 & 4 & 5 & 6 \\
\hline CB Q1 & 0,105 & $-0,060$ & 0,757 & 0,057 & 0,022 & $-0,115$ \\
CB Q3 & 0,063 & 0,086 & 0,756 & $-0,043$ & 0,024 & 0,109 \\
CB Q4 & $-0,088$ & 0,006 & 0,784 & $-0,009$ & 0,022 & $-0,096$ \\
SB Q1 & 0,006 & 0,936 & $-0,048$ & $-0,019$ & $-0,030$ & $-0,039$ \\
SB Q2 & 0,070 & 0,728 & 0,050 & 0,037 & 0,176 & $-0,056$ \\
SB Q3 & $-0,016$ & 0,599 & 0,188 & $-0,215$ & 0,001 & 0,013 \\
PB Q1 & 0,042 & 0,262 & $-0,037$ & 0,078 & 0,718 & $-0,005$ \\
PB Q2 & $-0,008$ & $-0,138$ & 0,100 & $-0,116$ & 0,901 & $-0,042$ \\
HB Q1 & 0,015 & $-0,040$ & $-0,057$ & $-0,967$ & 0,056 & $-0,036$ \\
HB Q2 & 0,056 & 0,117 & 0,053 & $-0,781$ & $-0,028$ & $-0,036$ \\
CE Q3 & 0,063 & 0,054 & 0,127 & $-0,050$ & $-0,019$ & $-0,827$ \\
CE Q4 & 0,002 & 0,004 & $-0,036$ & $-0,018$ & 0,027 & $-0,854$ \\
CC Q1 & 0,915 & $-0,055$ & 0,053 & $-0,043$ & 0,027 & 0,037 \\
CC Q2 & 0,963 & 0,063 & $-0,041$ & 0,023 & 0,011 & 0,011 \\
CC Q3 & 0,886 & $-0,015$ & 0,012 & $-0,024$ & $-0,042$ & $-0,095$ \\
\hline
\end{tabular}

Hedonic Benefits show to consist of an Enjoyable and Relaxing time and Fun and Pleasure, while problem-solving and idea-generation are not part of this construct. For the Customer Engagement questions in particular, the removed questions were about Importance and Relevancy of the use of a product or service. The included questions were about Meaning and Concern regarding products and services from the company. According to the factor analysis, Customer Engagement here is linked to long-term interactions and an emotional attachment instead of the use of a product itself.

In order to reduce measurement error, represent multiple facets of a concept and to optimize for prediction, Summated Scores were created based on the results from the Factor Analysis. (Table 2) For these scales, reliability and validity is verified in Table 3. Additionally, Divergent Validity was established in order to verify that the constructs are indeed different. With the constructs verified, it is then necessary to assess whether 
(multiple) linear regression can be done. Sample size requirements include N>100 and preferably 15-20 observations per independent variable which are met. In addition, each scale needs to be normally distributed and the independents have to be correlated to the dependent both are shown to be so for all scales.

Furthermore, this study analysed the four assumptions for linearity for each independent towards the dependent the Intention to Co-create existing out of: 1 Linearity of the phenomenon based on residual plot and plots of the independent towards the dependent itself. 2 Constant variance of error terms, using the residual plot and conducting Levene's tests in One-way ANOVA's. 3 Independence of error terms using the DurbinWatson statistic. And lastly 4 Normality of error terms, using the Histogram and Normal Probability plot of residuals. Examining these assumptions showed that Hedonic Benefits and Customer Engagement at first failed to achieve the second Constant Variance of Error Terms criterium. But after stabilizing the dependent variable with a natural logarithmic all assumptions are met for all variables.

Table 3. Reliability and AVE for each Factor

\begin{tabular}{|c|c|c|c|c|c|}
\hline Factor & Construct & Included & $\mathrm{A}>0.7$ & $\mathrm{CR}>0.7$ & $\mathrm{AVE}>0.5$ \\
\hline \multirow{3}{*}{1} & \multirow{3}{*}{ Cognitive Benefits } & CB-Q1 & 0,845 & 0,810 & 0,586 \\
\hline & & CB-Q3 & & & \\
\hline & & CB-Q4 & & & \\
\hline \multirow{3}{*}{2} & \multirow{3}{*}{ Social Benefits } & SB-Q1 & 0,873 & 0,806 & 0,588 \\
\hline & & SB-Q2 & & & \\
\hline & & SB-Q3 & & & \\
\hline \multirow{2}{*}{3} & \multirow{2}{*}{ Hedonic Benefits } & HB-Q1 & 0,917 & 0,870 & 0,773 \\
\hline & & HB-Q2 & & & \\
\hline \multirow{3}{*}{4} & \multirow{3}{*}{ Co-Creation } & CC-Q1 & 0,954 & 0,945 & 0,851 \\
\hline & & CC-Q2 & & & \\
\hline & & CC-Q3 & & & \\
\hline \multirow{2}{*}{5} & \multirow{2}{*}{ Personal Benefits } & PB-Q1 & 0,836 & 0,796 & 0,664 \\
\hline & & PB-Q2 & & & \\
\hline \multirow{2}{*}{6} & \multirow{2}{*}{ Customer Engagement } & CE-Q3 & 0,896 & 0,828 & 0,706 \\
\hline & & CE-Q4 & & & \\
\hline
\end{tabular}

With the constructs showing reliability, validity and the assumptions for linear regression met, the hypotheses for each independent towards dependent is tested. The first part of the hypotheses is about the possible influence of the Perceived Benefits onto the intention to Co-create on Facebook. The second part about Customer Engagement as possible mediator or moderator and the third part about Customer Engagement as a separate predictor. Single linear regression shows that every Perceived Benefit has a statistically significant $(\mathrm{p}<0.001)$ influence on the intention to Co-create, meaning that gratification does matter for the intention to Co-create and confirming the first set of hypotheses. Noteworthy is that Hedonics Benefits $(0.502, t$ value of 5.862) and Cognitive Benefits $(0.451, t$ value of 5.108) are the largest predictors. Social Benefits 
(0.380, $t$ value of 4.153) and Personal Benefits $(0.286, t$ value of 3.012) are smaller predictors of the intention to Co-create on Facebook.

Furthermore, Customer Engagement does not function as a mediator or moderator. Using it as such does not result in statistical significance and additionally results in multicollinearity issues in modelling which means that the second hypothesis is rejected. However, Customer Engagement does have a statistically significant $(p<0.001)$ influence on the intention to Co-create, confirming the third and last hypothesis. Moreover, Customer Engagement shows to have the largest influence $(0.539, t$ value of 6.471) on the intention to Co-create among the predictors.

\section{$6 \quad$ Analysis}

The model was created and tested in SPSS through the Enter method and verified using the Stepwise method. Using all four benefits and Customer Engagement as predictors showed a lack of statistically significant betas and adjusted $\mathrm{R}$ squared for Cognitive, Personal and Social Benefits. Finally, Customer Engagement and Hedonic Benefits proofed to be predictors of the intention to Co-create.

Fig. 3. Analysis Model

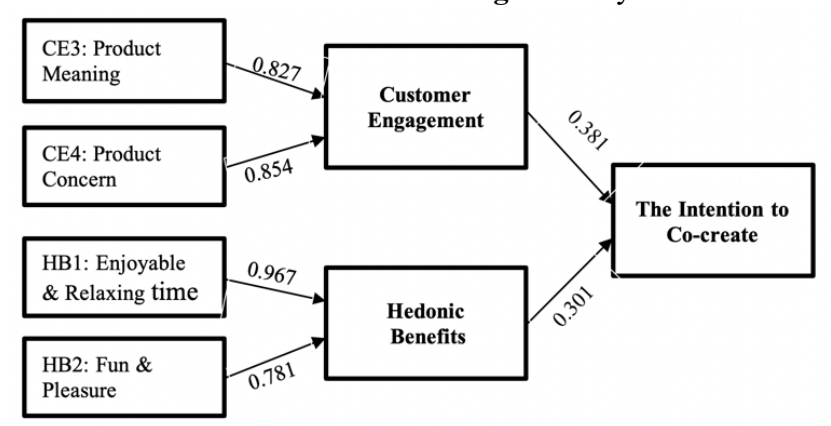

In order to further verify this model, a split sample of $60 \%: 40 \%$ was created randomly. Using the Enter method we verified Customer Engagement and Hedonic Benefits as significant predictors for both groups. Figure 3 shows the analysis model with the influence of each predictor on the intention to Co-create. Cognitive, Social and Personal benefits are not important in themselves to predict the intention to Co-create, perceived gratification is explained by Hedonic Benefits alone. Customer Engagement is a larger predictor than Hedonic Benefits, note that the included questions for Customer Engagement were about Product Meaning and Product Concern, both very relevant for Customer Engagement. People that find a company and its products meaningful and of concern to them are motivated to Co-create more than gratification does. The questions about Hedonic Benefits were about an Enjoyable and Relaxing time and a Fun and Pleasurable experience. 


\section{Discussion}

We delivered a predictive model for the intention to Co-create (Figure 3). Results show that each separate benefit does improve the intention to Co-create (Table 4), but remarkably, modelling showed that Hedonic Benefits are the most important and explain most of the perceived gratification. User Gratification does influence the intention to Co-create on Facebook, but not that much as Customer Engagement. Hedonic Benefits explains most of the gratification through the desire of people for an enjoyable and relaxing time. Customer Engagement functions as a separate independent factor. Hence, the factors Customer Engagement and Hedonic Benefits predict the intention to Co-create on Facebook.

Our results have various practical implications. In order to motivate customers to Co-create on Facebook, companies need to deliver Product Meaning and Product Concern. People are motivated by meaning, engagement with a company's products and by having fun while doing so for their intention to Co-creation. Customers want a meaningful experience in terms of long-term relationships with others, the company and its products. They want to feel an emotional connection with the company's products and want a pleasurable time. Gratification itself is not that important. Only Hedonic Benefits are significant as predictor in the model. Hedonic Benefits exists out of an Enjoyable and Relaxing time and a Fun and Pleasurable experience, while Problem Solving and Idea Generation are not fun for people here in contrast to previous studies [8,9].

With regard to theory, the differences between the underlying dimensions are actually quite different based on factor analysis. Customer Engagement is a predictor on its own instead of a mediator or moderator as theory suggests. Moreover, the results show that Meaning and Concern are relevant underlying dimensions, while Importance and Relevancy are not. This is different from previous research that showed all dimensions to be important $[8,9]$. The results mean that long-term relationships and an emotional attachment are important for Customer Engagement in this study.

Customer Engagement is about relationships and emotions, not about the use of a product or service. Intrinsic motivations with regards to meaning and concern may be more important than the extrinsic rewards gratification offers for Co-creation on Facebook. While Lee and Kim [8] did not use Customer Engagement as a possible predictor, we did and showed its importance. One could argue that meaning and concern are similar to benefits or gratification, but Factor Analysis showed that gratification and Customer Engagement are different constructs. Moreover, Discriminant Validity was established showing that Customer Engagement and Hedonic Benefits are separate constructs. In the end, Customer Engagement seems to be an important predictor for the intention to Co-create on Facebook and even better than gratification.

There are three important limitations regarding our findings. Firstly, we asked people about the intention to Co-create instead of participation data in Co-creation. For future research it may proof useful to consider what lies behind people's motivation for Co-creation. Secondly, while this research was carried out within Europe, other regions and other social media may provide different results. Finally, Co-creation could be studied in more detail when elaborating upon Meaning, Concern and intrinsic motivations over gratification and extrinsic motivations. 


\section{References}

1. Kaplan, A.M., Haenlein, M.: Users of the world, unite! The challenges and opportunities of Social Media. Bus. Horiz. 59-68 (2010).

2. Hennig-Thurau, T., Malthouse, E.C., Friege, C., Gensler, S., Lobschat, L., Rangaswamy, A., Skiera, B.: The impact of new media on customer relationships. J. Serv. Res. 13, 311-330 (2010).

3. Waters, R.D., Burnett, E., Lamm, A., Lucas, J.: Engaging stakeholders through social networking: How nonprofit organizations are using Facebook. Public Relat. Rev. 35, 102-106 (2009).

4. Cova, B., Dalli, D., Zwick, D.: Critical perspectives on consumers' role as "producers": Broadening the debate on value co-creation in marketing processes. Mark. Theory. 11, 231-241 (2011).

5. Grönroos, C., Voima, P.: Critical service logic: Making sense of value creation and cocreation. J. Acad. Mark. Sci. 41, 133-150 (2013).

6. Brodie, R.J., Ilic, A., Juric, B., Hollebeek, L.: Consumer engagement in a virtual brand community: An exploratory analysis. J. Bus. Res. 66, 105-114 (2013).

7. Brodie, R.J., Hollebeek, L.D., Jurić, B., Ilić, A.: Customer engagement: Conceptual domain, fundamental propositions, and implications for research. J. Serv. Res. 14, 252271 (2011).

8. Lee, A.R., Kim, K.K.: Customer benefits and value co-creation activities in corporate social networking services. Behav. Inf. Technol. 37, 675-692 (2018).

9. Nambisan, S., Baron, R.A.: Virtual Customer Environments: Testing a Model of Voluntary Participation in Value Co-creation Activities. J. Prod. Innov. Manag. 388406 (2009).

10. Muntinga, D.G., Moorman, M., Smit, E.G.: Introducing COBRAs: Exploring motivations for Brand-Related social media use. Int. J. Advert. 30, (2011).

11. Phua, J., Jin, S.V., Kim, J. (Jay): Gratifications of using Facebook, Twitter, Instagram, or Snapchat to follow brands: Telemat. Informatics. 34, 412-424 (2017).

12. Pappas, I.O., Papavlasopoulou, S., Kourouthanassis, P.E., Mikalef, P., Giannakos, M.N.: Motivations and emotions in social media: Explaining users' satisfaction with FsQCA. Lect. Notes Comput. Sci. (including Subser. Lect. Notes Artif. Intell. Lect. Notes Bioinformatics). 10595 LNCS, 375-387 (2017).

13. Etgar, M.: A descriptive model of the consumer co-production process. J. Acad. Mark. Sci. 36, 97-108 (2008).

14. Payne, A.F., Storbacka, K., Frow, P.: Managing the co-creation of value. J. Acad. Mark. Sci. 36, 83-96 (2008).

15. van Doorn, J., Lemon, K.N., Mittal, V., Nass, S., Pick, D., Pirner, P., Verhoef, P.C.: Customer engagement behavior: Theoretical foundations and research directions. J. Serv. Res. 13, 253-266 (2010).

16. Schau, H.J., Muñiz, A.M., Arnould, E.J.: How Brand Community Practices Create Value. J. Mark. 73, 30-51 (2009).

17. Kunz, W., et al.: Customer engagement in a Big Data world. J. Serv. Mark. 31, 161-171 (2017).

18. Dolan, R., Conduit, J., Fahy, J., Goodman, S.: Social media engagement behaviour: a 
uses and gratifications perspective. J. Strateg. Mark. 24, 261-277 (2016).

19. Malthouse, E.C., Haenlein, M., Skiera, B., Wege, E., Zhang, M.: Managing customer relationships in the social media era: Introducing the social CRM house. J. Interact. Mark. 27, 270-280 (2013).

20. Hoyer, W.D., Chandy, R., Dorotic, M., Krafft, M., Singh, S.S.: Consumer cocreation in new product development. J. Serv. Res. 13, 283-296 (2010).

21. Palmatier, R.W., Dant, R.P., Grewal, D., Evans, K.R.: Factors Influencing the Effectiveness of Relationship Marketing. J. Mark. 70, 136-153 (2006).

22. Sashi, C.M.: Customer engagement, buyer-seller relationships, and social media. Manag. Decis. 50, 253-272 (2012).

23. Kietzmann, J.H., Hermkens, K., McCarthy, I.P., Silvestre, B.S.: Social media? Get serious! Understanding the functional building blocks of social media. Bus. Horiz. 54, 241-251 (2011).

24. Hanna, R., Rohm, A., Crittenden, V.L.: We're all connected: The power of the social media ecosystem. Bus. Horiz. 54, 265-273 (2011).

25. Turri, A.M., Smith, K.H.: Developing affective brand commitment through social media. J. Electron. Commer. Res. 14, 201-215 (2013).

26. Rolland, S.E., Parmentier, G.: The benefit of social media: Bulletin board focus groups as a tool for co-creation. Int. J. Mark. Res. 55, 809 (2014).

27. Sorensen, A., Andrews, L., Drennan, J.: Using social media posts as resources for engaging in value co-creation: The case for social media-based cause brand communities. J. Serv. Theory Pract. 27, 898-922 (2017).

28. Westberg, K., Stavros, C., Smith, A.C.T., Munro, G., Argus, K.: An examination of how alcohol brands use sport to engage consumers on social media. Drug Alcohol Rev. 37, 28-35 (2018).

29. Huang, S., Chen, C.: How consumers become loyal fans on Facebook. Comput. Human Behav. 82, 124-135 (2018).

30. Jaakkola, E., Alexander, M.: The Role of Customer Engagement Behavior in Value CoCreation: A Service System Perspective. J. Serv. Res. 17, 247-261 (2014).

31. Nambisan, S.: Designing Virtual Customer Environments for New Product Development : Toward a Theory. Acad. Manag. Rev. 27, 392-413 (2002).

32. Pappas, I., Mikalef, P., Giannakos, M., Pavlou, P.: Value co-creation and trust in social commerce: An fsQCA approach. Proc. 25th Eur. Conf. Inf. Syst. 2017, 2153-2168 (2017).

33. Bryman, A., Bell, E.: Business Research Methods. Oxford University Press, Oxford (2015).

34. Saunders, M., Lewis, P., Thornhill, A., Booij, M., Verckens, J.P.: Methoden en technieken van onderzoek. Pearson Education Benelux, Amsterdam (2011).

35. Wolfswinkel, J.F., Furtmueller, E., Wilderom, C.P.M.: Using grounded theory as a method for rigorously reviewing literature. Eur. J. Inf. Syst. 45-55 (2013).

36. Spector, P.E.: Summated Rating Scale Construction. Sara Miller McCune, SAGE Publications, INC., Iowa City (1992).

37. Hair Jr, J.F., Black, W.C., Babin, B.J., Anderson, R.E.: Multivariate Data Analysis. Pearson Education Limited, Essex (2014). 